\title{
Urbanization and Spillover Effect for Three Megaregions in China: Evidence from DMSP/OLS Nighttime Lights
}

\author{
Xiaoxin Zhang ${ }^{1,2}$, Shan Guo ${ }^{1}$, Yanning Guan ${ }^{1, *}$, Danlu Cai ${ }^{1, *}$, Chunyan Zhang ${ }^{1}$, \\ Klaus Fraedrich ${ }^{3}$, Han Xiao ${ }^{2,4}$ and Zhuangzhuang Tian ${ }^{1,2}$ \\ 1 Institute of Remote Sensing and Digital Earth, Chinese Academy of Sciences, Beijing 100101, China; \\ zhangxx@radi.ac.cn (X.Z.); guoshan@irsa.ac.cn (S.G.); zhangcy@radi.ac.cn (C.Z.); \\ tianzhuangzhuang17@mails.ucas.ac.cn (Z.T.) \\ 2 University of Chinese Academy of Science, Beijing 100049, China; xiaoh@1reis.ac.cn \\ 3 Max-Planck-Institute for Meteorology, 20146 Hamburg, Germany; klaus.fraedrich@mpimet.mpg.de \\ 4 State Key Laboratory of Resources and Environmental Information System, Institute of Geographical \\ Sciences and Natural Resources Research, Chinese Academy of Sciences, Beijing 100101, China \\ * Correspondence: guanyn@radi.ac.cn (Y.G.); caidl@radi.ac.cn (D.C.); Tel.: +86-010-6488-9214 (Y.G.)
}

Received: 22 October 2018; Accepted: 22 November 2018; Published: 27 November 2018

\begin{abstract}
Urbanization drives human social development and natural environmental changes and shows complex implications for sustainability and challenges of future development, particularly in emerging countries. While extensive studies focus on extracting urban areas more precisely, less attention has been devoted to understand megaregion evolution and its related socioeconomic processes, not by socioeconomic statistics, but by comparing remote sensing based spatiotemporal evolution and the related spillover effect. Three main megaregions (with large area, high population and total gross domestic product) in China are selected for the analysis of development changes in an urbanization (magnitude, development)-diagram, of growth pattern changes based on Gravity Center and weighted Standard Deviation Ellipses and of the megaregions' spillover effect. Employing the spatiotemporally continuous lighted areas ( $\mathrm{DN} \geq 12)$ from the Defense Meteorological Satellite Program/Operational Linescan System (DMSP/OLS) nighttime signal (1992-2013) to the Beijing-Tianjin-Hebei (BTH), the Yangtze River Delta (YRD), and the Pearl River Delta (PRD) leads to the following results: (i) Developments in the (magnitude, development)-diagram indicate $25.97 \%, 45.95 \%$, and $39.10 \%$ of the first (high urbanization, fast development) class of the BTH, YRD, and PRD megaregions are rapidly developing into highly urbanized regions. The first class may slow down in the future like the second (high urbanization, slow development) class acting from 1992 to 2013, and the third (moderate urbanization, fast development) class shows potential to become the first class in the future. (ii) The original core function zones of YRD and PRD have highly developed till 1992 and expanding out with fast development from 1992 to 2013. Contrarily, BTH indicates more fast development toward the original core function zones while spatial expansion. (iii) The gravity distance evolution of the three megaregions shows a tendency towards the geometric distance 2013. However, YRD and PRD (BTH) indicate a light intensity expansion (concentration). This may relate to a positive spillover effect of YRD and PRD upon their neighbor cities, with the strongest signal in the early 21st Century and thereafter adjusting and followed by another positive spillover.
\end{abstract}

Keywords: urbanization; gravity center; standard deviational ellipse; spillover effect 


\section{Introduction}

Urbanization is a rapid and historic transformation of human social roots on a global scale [1]. More than one half of the world population lives now in urban areas, and virtually all countries of the world are becoming increasingly urbanized [2]. Nonetheless, this global phenomenon has very different expressions across regions and development levels. Emerging countries are still mostly rural and have urbanized faster than developed regions over the recent decades [3]. The land that is used for urban construction in China has expanded in all directions from the original core function zone in recent two decades, while no obvious urban area expanding pattern in the main city zone of America could be found $[4,5]$. Thus, urbanization induced changes of human settlement in emerging countries carry more complex implications for sustainability and development challenge [6-8].

As a new concept in urbanization, megaregions are becoming the new competitive units in the global economy for governments to implement novel strategies in the increasing movement of goods, people and capital among their metropolitan regions [9-11]. A megaregion is either organically formed or planned as a result of individual, collective, and political urban agglomerations [12,13]. These clustered networks of cities are not only physically coherent in space but also functionally linked through socioeconomic processes and share several or all of the following: environmental systems and topography, infrastructure systems, economic linkages, settlement and land use patterns, culture and history $[10,14]$. As the continuing increment and concentration of population, wealth, and infrastructure, megaregion changes/challenges should be investigated and quantified for understanding the related social and environmental effect, and therefore, to optimize urban planning and management [14-16].

Note that a megaregion includes some provinces entirely and others only partially. Thus, research on global/regional megaregions require the definition of urban land use, which can be different depending on the questions being addressed [4]. Traditionally, the definition of urban land use is mainly based on socio-demographic definitions using administrative boundaries, population size or density, and economic indicators [17-19]. However, identifying megaregions by socio-demographic indicators limits analyses in the administrative units, which hinders the exploration to obtain more comprehensive characteristics related to urban dynamics and associated environmental consequences during the urbanization processes $[20,21]$. However, remote sensing techniques that are employed to analyze urban dynamics detects the urbanization processes within administrative units in terms of physical definitions with the presence of human-made structures and materials on pixel scale [22-25]. Associated with multiple year comparisons, the spatiotemporal evolution of urbanization could be quantified in terms of intensity tendency, development pattern, and urban versus non-urban evolution [23,26,27].

Using the Defense Meteorological Satellite Program/Operational Linescan System (DMSP/OLS) nighttime light data to display the spatiotemporal changes of human settlement is a relatively recent field of research [28-32]. Efforts have been made to reveal the strong correlations between light intensity and socioeconomic development, including urban expansion [25,33], population growth [34,35], electric power consumption [36], and other socioeconomic indicators [20,37]. Attentions are gradually tending to nighttime light based megaregions to extract urban areas more precisely, such as built-ups [38], impervious surface areas [39], and to detect the spatial pattern changes and development inequality from urban expansion [40,41]. Generally, focusing on the spatial patterns inside megaregions makes quantification of the urbanization processes possible thereby calculating movements in the principle orientation, land use change direction, spatiotemporal intensity tendency, and degree of spatial dispersion. Characterizing the urbanization processes by quantitative measures is essential to direct urban planning and megaregion management [42-44] and to provide novel information for geosciences based urbanization research.

To achieve a comprehensive understanding of how China, as an emerging country, has urbanized over the recent decades (1992 to 2013), three main megaregions are displayed geographically and statistically. After introducing the data preprocessing of the remote sensing based DMSP/OLS nighttime light signals, methods of analysis including linear regression, Gravity Center calculation and Standard 
Deviational Ellipses are presented (Section 2). The spatiotemporally internal and integral pattern evolutions of megaregions are discussed in terms of light intensity tendencies based development changes and land use based growth pattern changes (Section 3), followed by a concluding summary and discussion (Section 4).

\section{Data and Methods of Analysis}

The DMSP/OLS nighttime stable light data (version 4, provided by National Geophysical Data Center of National Oceanic and Atmospheric Administration) are gridded cell-based annual cloud-free composites. It is available from 1992 to 2013 with a spatial resolution of $30^{\circ} \times 30^{\circ}$ arc-second (approximately $1 \times 1 \mathrm{~km}^{2}$ at the equator), and of digital value ranges from 0 to 63 . The datasets are archived by multiple DMSP satellites (F10, F12, F14, F15, F16, F18) with data overlapping and the original total sum of nighttime light from different satellites shows discrepancies in the same year. Thus a data preprocessing is required to make the values among different satellites and different years to be continuous and comparable [28,31].

\subsection{Data Pre-Processing}

Calibration among different satellites: The Invariant Region Method is used to reduce data inconsistency among different satellites (inter-calibration, see [28,45]). It constructs a quadratic polynomial regression model to empirically adjust the observed values to match the reference imagery, $D N_{\text {calibrated }}$ $=C_{0}+C_{1} \times D N+C_{2} \times D N^{2}$ (see [28]), where $D N\left(D N_{\text {calibrated }}\right)$ is the original (inter-calibrated) value, and $C_{0}, C_{1}$ and $C_{2}$ are defined by a regression model depending on $D N$ of the related dataset. Note that images in Mauritius, Puerto Rico, and Okinawa (Japan) are serving as the invariant regions, and Satellite F16 for 2007 are selected as reference imagery (see [45]) and all regression models are conducted with $R^{2}>$ 0.89 in this study.

Calibration among different years: Both intra- and inter-annual calibrations are implemented [46] (i) to remove unstable lit pixels among different satellites by averaging the overlapping stable lit values: $D N_{(y r, i)}=\left(D N_{(y r, i)}^{s 1}+D N_{(y r, i)}^{s 2}\right) / 2$, and (ii) satellite inconsistencies within multiple years, and thus to detect the actual megaregion development:

$$
D N_{(y r, i)}=\left\{\begin{array}{cc}
0 & D N_{(y r+1, i)}=0 \\
D N_{(y r-1, i)} & D N_{(y r+1, i)}>0 \& D N_{(y r-1, i)}>D N_{(y r, i)} \\
D N_{(y r, i)} & \text { otherwise }
\end{array}\right.
$$

where $D N_{(y r, i)}$ represents the $i$ th lit pixel value of the nighttime light data in an individual year yr, $S_{1}$ and $S_{2}$ represent different satellites.

\subsection{Methods of Analyses}

Both megaregion scale and city scale are selected for investigating the state of urbanization, the overall growth pattern, and the development of unevenness within cities. To reduce the effect of over-glow that is caused by anthropogenic activities in undeveloped areas, the spatial continuous lighted areas with DN $\geq 12$ are considered as megaregions [30,31]; for more detailed information on data quality control and threshold determining see [32]. Some cities within administrative boundaries do not contribute to the megaregions (or not belong to the spatial continuous lighted areas), whereas statistics of individual cities supplement for understanding of megaregion induced social and environmental effect and therefore to optimize urban planning and management.

To estimate the long-term megaregion development, a linear regression analysis is employed to determine the light intensity tendency (slope) from the time development on pixel scale $[25,40]$ and the results are subjected to an $F$-test with all significance levels on the $p$-value $<0.05$ level (unless noted otherwise). Associated with the final light magnitude in the year 2013, the megaregion development is categorized in terms of a matrix of classes characterizing both the state (magnitude of urbanization) and its 
change (development or tendency of urbanization): Six classes are introduced combining three types of the final light magnitude (high, moderate, and low urbanization) and two types of development tendencies (fast and slow development); non-significant regions and dark areas are classified as undeveloped zones. The Jenks Natural Breaks Classification Method [47] is applied for threshold definition.

Growth pattern changes on the megaregion and city scale are characterized by two measures: the changes of Gravity Center [48] and of Standard Deviational Ellipse [49]: the concept of Gravity Center is used to identify the weighted center of megaregions and cities; and the Standard Deviational Ellipse is used to measure the spatial orientation of urban light intensity distribution and dispersion. Generally, associated with the 22 years datasets, spatial growth pattern evolution can be traced by four parameters, including the Gravity Center, azimuth/rotation angle, lengths of major and minor axis and the spatial spillover effect within megaregions estimated by the total sum of the Euclidean distances between the Gravity Center of inner cities and the Gravity Center of the megaregion (equations presented in Table 1).

Table 1. Equations of the growth pattern change in megaregion scale and city scale (Gravity Center [48] and Standard Deviational Ellipse [49]). Pixel value $D N_{i}$ and its geographic coordinates of $\left(x_{i}, y_{i}\right)$ are used to calculate the Gravity Center in megaregion scale $(\bar{X}, \bar{Y})$ or a city scale $\left(\bar{X}_{\text {city }}, \bar{Y}_{\text {city }}\right)$, where $n$ represents the related scale pixel number, $\theta$ is the azimuth of the weighted Standard Deviational Ellipse, indicating the angle measured clockwise from the North to the major axis of the ellipse. The major (minor) axis is calculated using the standard deviation in the $\theta$ direction (perpendicular to $\theta$ ), which corresponds to the dispersion degrees of geographical features in the major and minor direction, respectively $\widetilde{x}_{i}=x_{i}-\bar{X}$ and $\widetilde{y}_{i}=y_{i}-\bar{Y}$, which refers to the distance of the $i$ th pixel to the Gravity Center. The total sum of the Euclidean distances, (SumDis) between the Gravity Center of individual city $\left(\bar{X}_{c i t y}, \bar{Y}_{\text {city }}\right)$ and the Gravity Center of the megaregion $(\bar{X}, \bar{Y})$ represents urban Gravity Distance, where $c n$ represents the related city number.

\begin{tabular}{cc}
\hline Parameter & Equation \\
\hline Gravity Center & $\bar{X}=\left(\sum_{i=1}^{n} D N_{i} \times x_{i}\right) /\left(\sum_{i=1}^{n} D N_{i}\right), \bar{Y}=\left(\sum_{i=1}^{n} D N_{i} \times y_{i}\right) /\left(\sum_{i=1}^{n} D N_{i}\right)$ \\
Azimuth angle & $\tan \theta=\frac{\left(\sum_{i=1}^{n} D N_{i}^{2} \widetilde{x}_{i}^{2}-\sum_{i=1}^{n} D N_{i}^{2} \widetilde{y}_{i}^{2}\right)+\sqrt{\left(\sum_{i=1}^{n} D N_{i}^{2} \widetilde{x}_{i}^{2}-\sum_{i=1}^{n} D N_{i}^{2} \widetilde{y}_{i}^{2}\right)+4\left(\sum_{i=1}^{n} D N_{i}^{2} \widetilde{x}_{i}^{2} \tilde{y}_{i}^{2}\right)^{2}}}{2 \sum_{i=1}^{n} D N_{i} \widetilde{x}_{i} \tilde{y}_{i}}$ \\
Major (minor) axis & $\sigma_{x}=\sqrt{\frac{\sum_{i=1}^{n}\left(D N_{i} \widetilde{x}_{i} \cos \theta-D N_{i} \widetilde{x}_{i} \sin \theta\right)^{2}}{\sum_{i=1}^{n} D N_{i}^{2}}, \sigma_{y}=\sqrt{\frac{\sum_{i=1}^{n}\left(D N_{i} \widetilde{y}_{i} \cos \theta-D N_{i} \widetilde{y}_{i} \sin \theta\right)^{2}}{\sum_{i=1}^{n} D N_{i}^{2}}}}$ \\
Gravity Distance & SumDis $=\sum_{c i t y=1}^{c n}\left(\sqrt{\left(\bar{X}_{c i t y}-\bar{X}\right)^{2}+\left(\bar{Y}_{c i t y}-\bar{Y}\right)^{2}}\right)$ \\
\hline
\end{tabular}

\section{Results and Discussion}

Three largest urban areas in China are selected in terms of their administrative boundaries (see Figure $1 \mathrm{~b}-\mathrm{d}$ ), which have undergone rapid urbanization over the recent decades: the BeijingTianjin-Hebei (BTH with 13 cities), the Yangtze River Delta (YRD with 14 cities) and the Pearl River Delta (PRD with 10 cities). Although they occupy only 5.2\% of the national territory, nearly one-quarter of Chinese total population and two-fifths of the total gross domestic product are generated in the three megaregions (Figure 1a, see also the 2014 National Statistics Yearbook of China). The Beijing-Tianjin-Hebei is situated in the Northern China Plain embedded by high mountains in the northwest (Taihang and Yan, Figure 1b). The Yangtze River Delta is located in the Yangtze River alluvial plain with an average elevation below 100m in the north and several hills in the south (Figure 1c). The Pearl River Delta is surrounded by undulating hills and the confluence of three large rivers (Figure 1d). After calibration (see Section 2.1), the continuity and comparability of nighttime light data among different satellites have been improved to detect long term urbanization processes. First, nighttime light intensity is extracted to analyze the spatiotemporal tendency of urban development of the whole administrative regions (for boundary information see Figure 1b-d); 22 years of nighttime stable light based land use classification 
$(D N \geq 12)$ reveals the urbanization evolution in both the megaregion and city scale, so that their related growth patterns could be quantified (employing the methods presented in Section 2.2, Table 1).

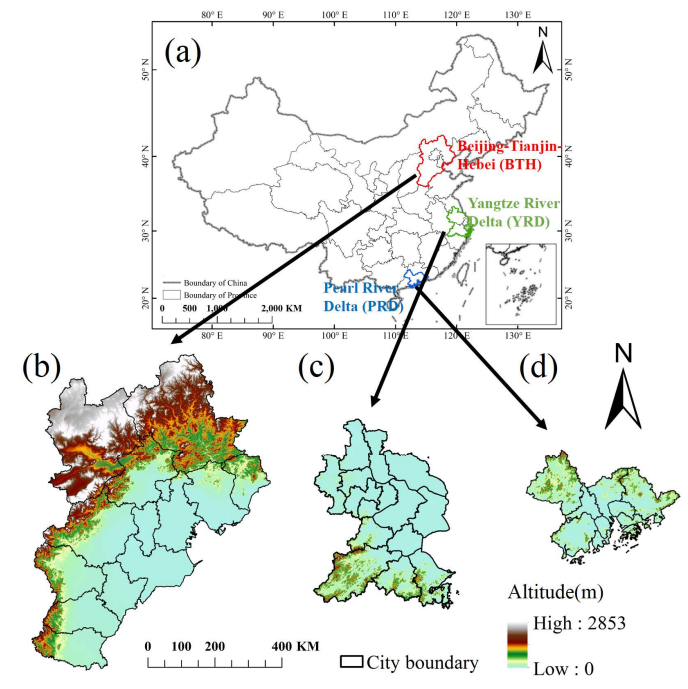

Figure 1. Geographical location (a) and topographical setting of Beijing-Tianjin-Hebei (b), Yangtze River Delta (c), and Pearl River Delta (d).

\subsection{Light Intensity Tendency based Development Changes}

Nighttime light intensity data in the year 2013 is used to reflect the urbanized magnitude (Figure 2, the upper row) and tendency from 1992 to 2013 of nighttime light intensity indicates the development speed with the slope calculated from linear regression (Figure 2, the second row). The spatial heterogeneity of the urbanization development magnitude and tendency show the following results:

Magnitude: The night intensity dataset within the administrative boundary shows a Gaussianlike distribution which implies that high values are concentrated in the original urban core, whereas attenuation occurs in all surrounding area. As the spatially continuous lighted areas in 2013 with $D N \geq 12$ are considered as megaregions, the megaregion of Beijing-Tianjin-Hebei (Yangtze River Delta and Pearl River Delta) including the administrative city areas of Beijing, Tianjin, Langfang, Tangshan, Baoding, Qinhuangdao, and Cangzhou (all 14 cities and all 10 cities) partially occupying areas of $38,204 \mathrm{~km}^{2}\left(58,926 \mathrm{~km}^{2}\right.$ and $\left.25,558 \mathrm{~km}^{2}\right)$. Some cities within the administrative boundaries of the Beijing-Tianjin-Hebei are not included to the megaregions (spatially continuous lighted areas), but discretely distributed with as well high intensity values in the original urban cores (Figure 2a). That is, there may be more difficulties to implement strategies for those cities to be functionally linked into the megaregion's socioeconomic processes.

Development: The light intensity tendency (1992 to 2013) indicates the opposite of the night magnitude distribution, which implies that low values are in the original urban core whereas amplification occurs in the surrounding area (see the yellow circle and orange ring in the second row of Figure 2), followed by a gray attenuation later after the orange ring. That is, the original urban cores show slow development in past decades while the surrounding zones undergo a fast development, followed by an attenuation to zero slope regions. The zero slope regions correspond to the mountainous areas in Figure 1. The saturation of the development in the original urban core forces a fast developing speed in the surrounding emerging areas which is consistent with findings from previous studies that the land used for urban construction in China has expanded in all directions from the original core [4]. Development (or changes) in administrative boundaries (third row) and megaregions (bottom row) in Figure 2 is based on the statistics of the tendencies of light intensity:

(i) The average development speed in the megacities of the Beijing-Tianjin-Hebei, the Yangtze River Delta and the Pearl River Delta (in the relative administrative boundary) are $0.84,1.28$, and 
$1.02(0.30,0.87,0.60) \mathrm{DN} / \mathrm{yr}$, respectively. Increments in the three megaregions (in the administrative boundary) in terms of positive slope account for $100 \%(57.22 \%, 87.49 \%$, and $78.47 \%)$ of the total region area with the average standard deviations of $0.67,0.85$, and $0.69(0.47,0.85$, and 0.68$) \mathrm{DN} / \mathrm{yr}$, respectively. That is, in terms of both urbanized magnitude and development, urbanization changes are largest for the Yangtze River Delta followed by Pearl River Delta and Beijing-Tianjin-Hebei.

(ii) On the city scale (embedded in the megaregions), discrepancies can be found in both urbanization average magnitude and its change (development), see Table 2. Within the Beijing-Tianjin-Hebei megaregion, the cities of Beijing, Tianjin, Tangshan, Qinhuangdao, Langfang, Baoding, and Cangzhou are embedded in the megaregions. Note that Suzhou is the city with the highest development speed in the recent decade, and Hong Kong is the city with the slowest development speed but high urbanization since 1992.

(iii) Several cities within the Beijing-Tianjin-Hebei administrative boundaries are not included in the megaregion; these are Handan, Shijiazhuang, Xingtai, Hengshui, Zhangiiakou, and Chengde with their average development of (magnitude, development)-diagrams of $(16.08,0.33),(13.34,0.21),(11.92,1.22)$, $(10.63,0.21),(2.93,0.10)$, and $(2.07,0.07)$ in $(D N, D N / y r)$-units, respectively. Compared with the cities in megaregion, these cities are located in Hebei province and show a low development speed from 1992 to 2013. In addition, urbanization and anthropogenic activities are low in Zhangjiakou and Chengde where the natural environment has been preserved [50]. That is, unlike magnitude and tendency in Yangtze River Delta and Pearl River Delta, cities within the Beijing-Tianjin-Hebei administrative boundaries show an uneven development. This development difference leads to the question how cities evolve spatially into a megaregion and how the megaregion will develop in the future.

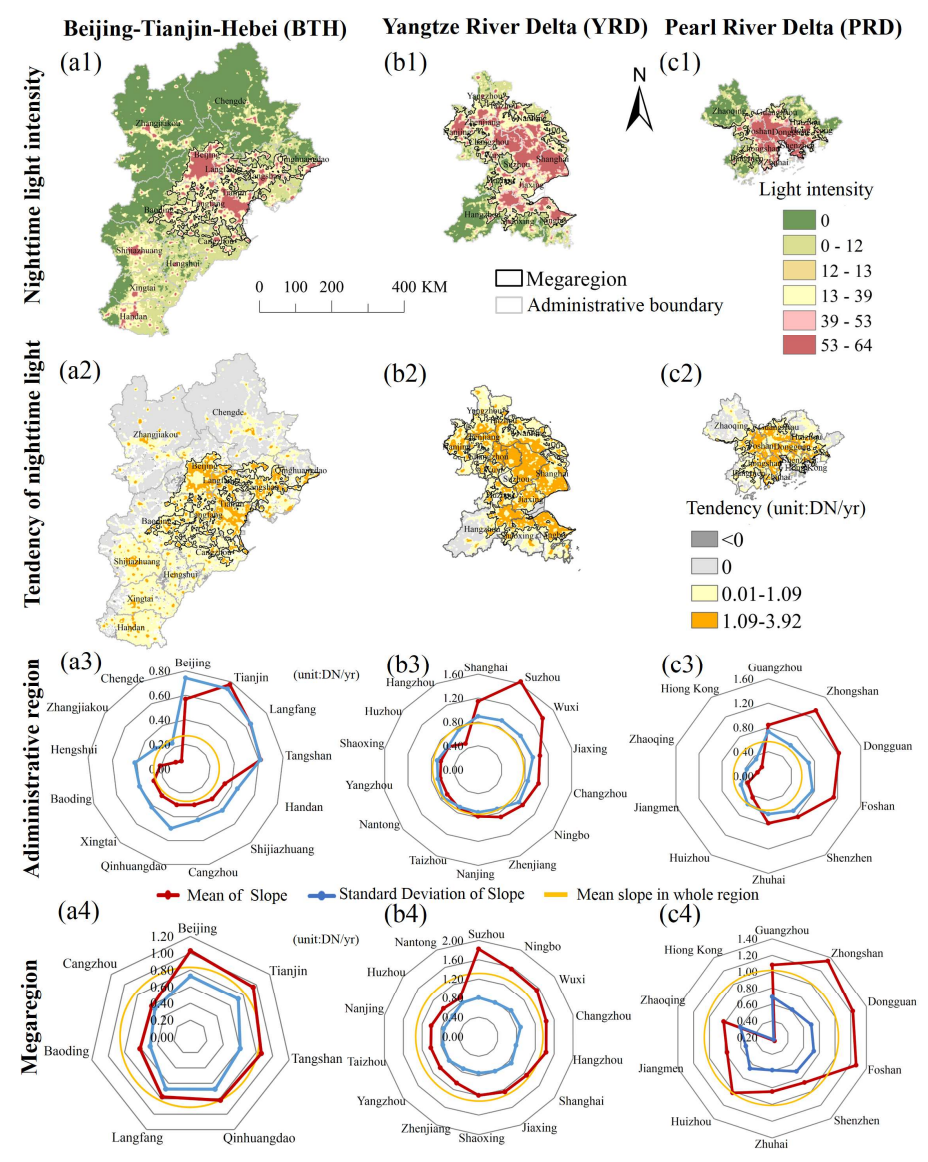

Figure 2. Geographical distribution of calibrated light intensity in 2013 (upper row: a1-c1), 22 years linear regression tendency of light intensity (from 1992 to 2013 in DN/yr, second row: a2-c2), and statistics of linear regression tendency for individual cities in both administrative (third row: a3-c3) and megaregion (bottom row: a4-c4) boundaries. 
Table 2. The (magnitude, development)-diagrams in units of ( $D N, D N / y r)$ for each city in the three megaregions.

\begin{tabular}{cccccc}
\hline \multicolumn{2}{c}{ Beijing-Tianjin-Hebei } & \multicolumn{2}{c}{ Yangtze River Delta } & \multicolumn{2}{c}{ Pearl River Delta } \\
\hline City & $\begin{array}{c}\text { (Magnitude, } \\
\text { Development) }\end{array}$ & City & $\begin{array}{c}\text { (Magnitude, } \\
\text { Development) }\end{array}$ & City & $\begin{array}{c}\text { (Magnitude, } \\
\text { Development) }\end{array}$ \\
\hline Beijing & $(44.07,1.03)$ & Shanghai & $(47.99,1.27)$ & Guangzhou & $(45.07,1.08)$ \\
Tianjin & $(36.97,0.95)$ & Suzhou & $(49.34,1.82)$ & Zhongshan & $(53.01,1.35)$ \\
Tangshan & $(28.28,0.86)$ & Wuxi & $(46.17,1.54)$ & Dongguan & $(58.51,1.23)$ \\
Qinhuangdao & $(32.80,0.82)$ & Changzhou & $(41.97,1.43)$ & Foshan & $(51.02,1.27)$ \\
Langfang & $(28.92,0.77)$ & Jiaxing & $(29.37,1.06)$ & Shenzhen & $(54.38,0.83)$ \\
Baoding & $(24.44,0.61)$ & Ningbo & $(23.03,0.95)$ & Zhuhai & $(36.62,0.62)$ \\
Cangzhou & $(24.97,0.59)$ & Zhenjiang & $(29.48,0.88)$ & Huizhou & $(15.02,0.58)$ \\
& & Nanjing & $(27.91,0.78)$ & Jiangmen & $(14.57,0.44)$ \\
& & Taizhou & $(23.98,0.72)$ & Zhaoqing & $(6.57,0.22)$ \\
& & Nantong & $(24.19,0.66)$ & Hong Kong & $(53.97,0.15)$ \\
& & Yangzhou & $(20.63,0.65)$ & & \\
& Shaoxing & $(16.06,0.64)$ & & \\
\end{tabular}

To reveal the spatiotemporal urban growth pattern (see Section 2.2 and Figure 3), an urbanization (magnitude, development)-diagram is introduced to categorize each pixel into five classes: first (high urbanization, fast development), second (high urbanization, slow development), third (moderate urbanization, fast development), fourth (moderate urbanization, slow development), and fifth (low urbanization, slow development). Note that there is no (low urbanization, fast development)-type in the study regions (DN thresholds are 13 and 39, and the slope threshold is 1.1 according to the Jenks Natural Breaks Classification Method [47]). The following results are noted (classes remain in the same order unless notified):

(i) Within the Beijing-Tianjin-Hebei (Yangtze River Delta and Pearl River Delta) administrative boundary, the five classes of (magnitude, development) occupy $6.26 \%, 2.43 \%, 1.25 \%, 16.69 \%, 22.41 \%(26.92 \%$, $4.21 \%, 3.71 \%, 24.40 \%, 23.30 \%$ and $17.84 \%, 12.06 \%, 2.18 \%, 15.85 \%, 21.33 \%)$ of the administrative areas. The fourth (moderate urbanization, slow development) and the fifth class (low urbanization, slow development) show high percentage in all three regions. The first class (high urbanization, fast development) reveals high percentage in the Yangtze River Delta and the Pearl River Delta which, when compared with the Beijing-Tianjin-Hebei megaregion, indicates a fast development since 1992. The high percentage of the second class (high urbanization, slow development) represents a highly developed state of the Pearl River Delta in 1992, which is in agreement with the previous studies [51,52].

(ii) Within the Beijing-Tianjin-Hebei (the Yangtze River Delta versus the Pearl River Delta) megaregion, the five development classes in (magnitude, development)-diagram occupy $25.97 \%, 9.69 \%$, $4.26 \%, 53.31 \%, 6.77 \%(45.95 \%, 7.24 \%, 5.96 \%, 37.39 \%, 3.46 \%$ versus $37.91 \%, 25.55 \%, 4.41 \%, 29.60 \%$, $2.53 \%$ ) of the megaregion areas. The first (high urbanization, fast development) class indicates that after a development in the recent decades, $25.97 \%, 45.95 \%$, and $37.91 \%$ of the Beijing-Tianjin-Hebei, the Yangtze River Delta and the Pearl River Delta megaregions are rapidly developed into high urbanized regions. The first (high urbanization, fast development) class may slow down its development in the future, like the second (high urbanization, slow development) class acting from 1992 to 2013; 4.26\%, $5.96 \%$, and $4.41 \%$ of the third class (moderate urbanization, fast development) show potential to become the first (high urbanization, fast development) class in the future.

(iii) On the city scale (Figure 3 middle row) a lower percentage of fast development could be found in the cities belonging to Beijing-Tianjin-Hebei. Even for Beijing city, the fast development class accounts for about 20\%. However, cities in the Yangtze River Delta, for example, Shanghai, Suzhou, and Wuxi account for the first class (high urbanization, fast development) of $45.59 \%, 62.24 \%$, and $53.41 \%$, respectively. Cities in the Pearl River Delta, such as Guangzhou, Zhongshan, and Dongguan, account for the first class (high urbanization, fast development) of $32.15 \%, 61.27 \%$, and $51.00 \%$. In addition, Hong Kong, Shenzhen, and Dongguan in the Pearl River Delta have the relatively high percentage of 
second (high urbanization, slow development) class $(70.71 \%, 55.36 \%$, and $44.19 \%)$, which indicate their highly developed status in 1992. Zhangjiakou and Chengde in Beijing-Tianjin-Hebei show 84.64\% and $87.26 \%$ of zero tendency (or non-significant slope) areas, which is in agreement with the average development of the (magnitude, development)-diagrams in Figure 2 and comparable with local relatively less urbanization processes or anthropogenic activities (found by [50]).

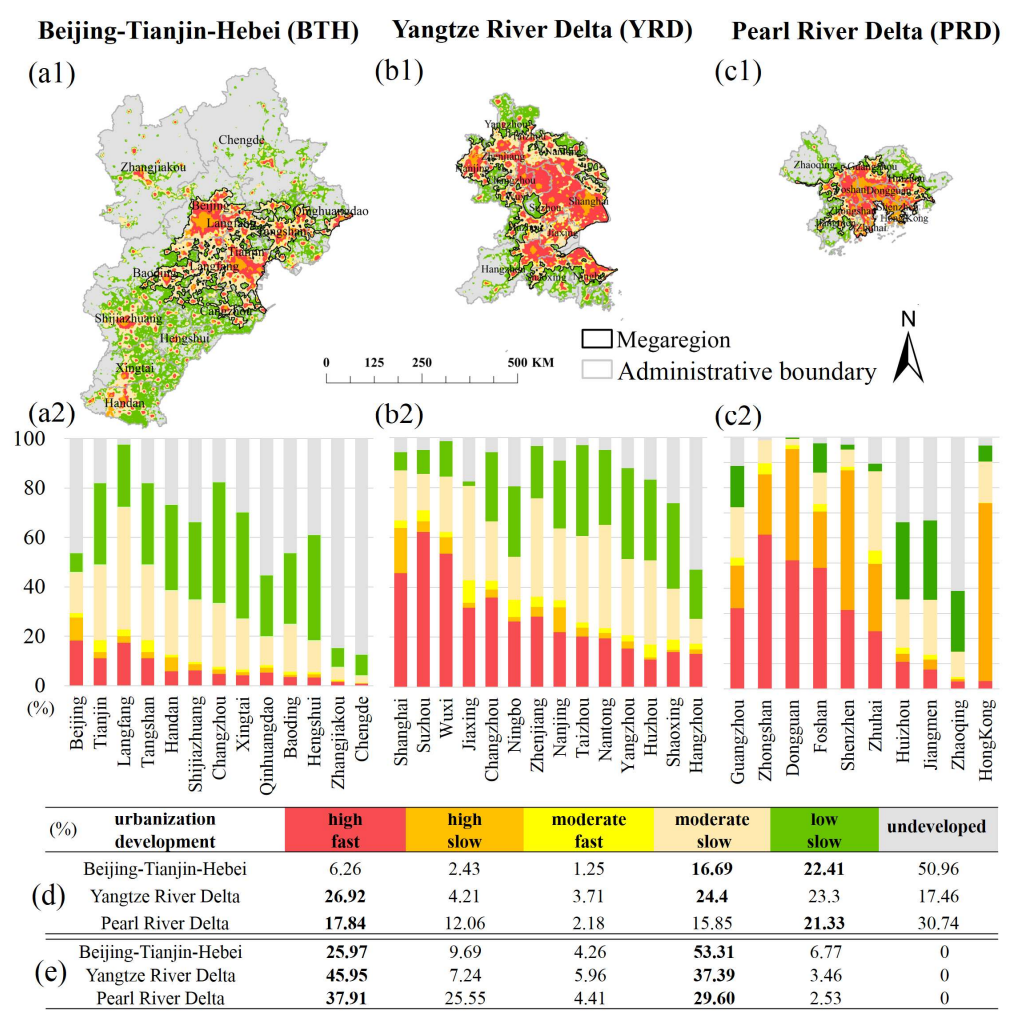

Figure 3. Geographical distribution of five classes of urbanization (magnitude, development)-diagram of urbanization on pixel scale (upper row: a1-c1): (1) red (high urbanization, fast development), (2) orange (high urbanization, slow development), (3) yellow (moderate urbanization, fast development), (4) beige (moderate urbanization, slow development), and (5) green (low urbanization, slow development). Related city scale statistics (defined by administrative boundary) are shown in the middle row (a2-c2). Statistics comparison within two administrative boundaries (d) and megaregions (e) are shown in bottom in percentage.

\subsection{Urban Development: A Standard Deviational Ellipse Analysis}

To quantify impacts of anthropogenic activities on land surface dynamics in China's three largest megaregions, Gravity Center (Figure 4, middle row) and Standard Deviational Ellipse (Figure 4, bottom row and Table 3) in megaregion scale are introduced (see Section 2.2). The Gravity Center of the BeijingTianjin-Hebei megaregion is located in Langfang and the border of Beijing, Tianjin, and Baoding. It goes from the North to the South before 2002 and then moves towards the East, followed by another South moving tendency, and finally overlays with the Geometric Center after 2009. There is a leading direction from Northwest to Southeast could be found in the 22 years due to a relatively high development in Langfang and Tianjin (see Figure 3). The Gravity Centers of the Yangtze River Delta megaregion are located in Suzhou showing a Southeast tendency from 1992 to 2002, and then moving to the Northwest approaching the Geometry Center of the megaregion. That is, before (after) 2002, cities in the Southeast (Northwest) show relatively high developments, particularly in Shanghai and Jiaxing (Wuxi and Changzhou). The Gravity Centers of the Pearl River Delta megaregion are located at the border of Guangzhou, Dongguan, and Zhongshan. The trajectories of changes demonstrate a Northwest tendency toward Guangzhou due to a regional coastal limitation and a relatively high development in Guangzhou. 
Generally, the trajectories of Gravity Center changes in the three megaregions are related to regional developments (see the red bars in Figure 3 middle row and [44,51]) and toward their Geometric Centers.

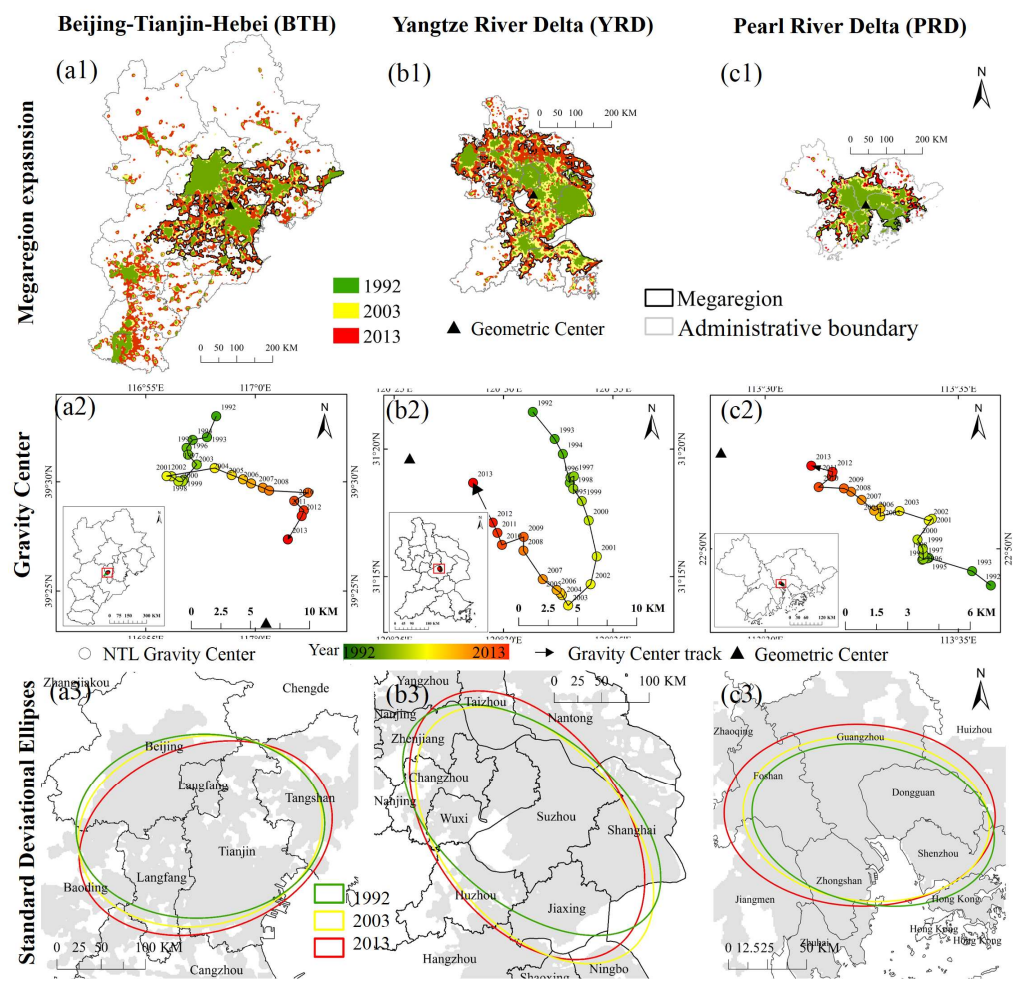

Figure 4. Geographical distribution of urbanization expansion employing the calibrated spatiotemporally continuous lighted areas (DN $\geq 12$ ) in upper row (a1-c1): 1992 (green), 2003 (yellow) and 2013 (red). Gravity Center trajectories (from 1992 to 2013, middle row: a2-c2) and the related Weighted Standard Deviational Ellipses (bottom row: a3-c3) in megaregion scale combined with gray megaregions as background. Note that circles represent the trajectory of the annual Gravity Centers of nighttime lights and the triangles show Geometric Center in 2013.

Table 3. Statistics of the Weighted Standard Deviation Ellipse parameters in the three megaregions of the Beijing-Tianjin-Hebei (BTH), the Yangtze River Delta (YRD) and the Pearl River Delta (PRD) for the years 1992, 2003 and 2013, including major and minor axes, areas, azimuth/rotation angle.

\begin{tabular}{cccccc}
\hline Megaregion & Year & $\begin{array}{c}\text { Major Axis } \\
\mathbf{( k m )}\end{array}$ & $\begin{array}{c}\text { Minor Axis } \\
\mathbf{( k m )}\end{array}$ & $\begin{array}{c}\text { Major Axis/Minor } \\
\text { axis }\end{array}$ & $\begin{array}{c}\text { Rotation } \\
\text { Angle } \mathbf{(}^{\circ} \mathbf{)}\end{array}$ \\
\hline \multirow{3}{*}{ Beijing-Tianjin-Hebei } & 1992 & 140.52 & 80.20 & 1.75 & 88.59 \\
& 2003 & 138.31 & 82.80 & 1.67 & 84.36 \\
Yangtze River Delta & 2013 & 144.42 & 82.31 & 1.75 & 79.81 \\
& 1992 & 150.42 & 81.78 & 1.84 & 120.64 \\
Pearl River Delta & 2003 & 145.81 & 88.73 & 1.64 & 129.90 \\
& 2013 & 145.48 & 93.92 & 1.55 & 133.29 \\
& 1992 & 78.14 & 46.88 & 1.67 & 99.38 \\
& 2003 & 78.92 & 48.45 & 1.63 & 95.36 \\
\hline
\end{tabular}

Spatial growth pattern evolution in terms of weighted Standard Deviational Ellipse based Gravity Center, azimuth, major and minor axes is diagnosed to simulate the presence of human-made structure changes with an ellipse in both megaregion scale and city scale. In this study, megaregion in 1992 (green in Figure 4, upper row) is defined as the original core function zones and the frame of reference for comparing is the megaregion in 2013. From 1992 to 2013 (green to red) the original core function zones of YRD and PRD have expanded out and BTH shows spatial expansion in between Beijing and Tianjin. Decadal ellipses with one standard deviation are drawn (1992, 2003, and 2013, see Equations (2) 
to (4)) to quantify the expansion with the orientation angle $\theta$ and the ratio of the major to the minor axes. The orientation angle $\theta$ represents the main construction direction and the ratio of the major to the minor axes length highlights the development ratio of the main construction direction to the perpendicular direction. The following are noticed:

(i) Within the Beijing-Tianjin-Hebei megaregion, the main construction direction $\theta$ shows an anticlockwise shift from the $88.59^{\circ}$ to $79.81^{\circ}$, and the development ratio decreases first and then increases in the major direction to keep a balanced construction. This may be related to both the regional development and the geographical limitation by the mountainous area in the northwest (Taihang and Yan mountains) and the southeastern Bohai Bay framing the northern China Plain (Figure 1b).

(ii) In the Yangtze River Delta megaregion, a clockwise shift of the main construction direction $\theta$ increases from $120.64^{\circ}$ to $133.29^{\circ}$, which is similar to its Gravity Center evolution in Figure 4 showing an intensity enhancement in the Northwest till 2013. In addition, unlike the major length decreasing, the minor axis length has been increasing over the 22 years and so has the urban construction increased in the direction perpendicular to the major axis.

(iii) In the Pearl River Delta megaregion, the lengths of major and minor axes are positively related with some small changes of the development ratio from 1992 to 2013. The main construction direction $\theta$ decreasing from $99.38^{\circ}$ to $91.32^{\circ}$ is related to the highly developed original status of Hong Kong, and the Shenzhen (see also Figure 3, the percentage of the second (high urbanization, slow development) class accounts for $70.71 \%$, and $55.36 \%$ respectively) and the fast development of Guangzhou and Dongguan (see also Figure 3).

Inner changes in the city scale are also calculated to demonstrate the urban development diversity (shown in Appendix A Figure A1). In the Beijing-Tianjin-Hebei megaregion, the main construction directions show a clockwise rotation in Beijing, Tianjin, Langfang, Tangshan, and Qinhuangdao associating with an urban development extending in the southeast direction (see also Figure 2). In the Yangtze River Delta megaregion, Shanghai, Suzhou, Wuxi, Yangzhou, Taizhou, and Huzhou show an expansion in both major and minor axis directions associated with a clockwise rotation. Guangzhou, Foshan, Zhuhai, and Huizhou in the Pearl River Delta megaregion show also expansion in both major and minor directions, while Hong Kong, Shenzhen, and Dongguan remain almost constant in direction of both major and minor axes associated with a high percentage of the second class (high urbanization, slow development, see Figure 3).

\subsection{Spillover Effect of Megaregion on Surrounding Cities}

Extensive studies on the relationship between inner cities and megaregions focus on socioeconomic processes [53,54], whereas less attention has been devoted to the spatial evolution of inner cities to describe the spillover effect of a megaregion on its surrounding cities. This spillover effect, as measured by the sum of the Euclidean Distance between the nighttime light based Gravity Center of the inner cities to the Gravity Center of a megaregion, is used to explore the discrepancy within a megaregion (Gravity Distance see Figure 5). In addition, the total distances between the Geometric Center of the megaregion and the internal cities (2013) are calculated for comparison (named Geometric Distance hereafter). The main results are as follows:

(i) The Geometric Distance in the Beijing-Tianjin-Hebei (the Yangtze River Delta versus the Pearl River Delta) megaregion is $842.15 \mathrm{~km}(1626.07 \mathrm{~km}$ versus $724.17 \mathrm{~km})$, while the Gravity Distance in Beijing-Tianjin-Hebei (Yangtze River Delta versus Pearl River Delta) is in a range from 857.24 to $894.38 \mathrm{~km}$ (1604.69 to $1623.48 \mathrm{~km}$ versus 675.41 to $696.76 \mathrm{~km}$ ). The Gravity Distance evolution of the three megaregions shows a tendency toward the Geometric Distance (2013) with some fluctuations. Note that the Gravity Distance will be the same as the Geometric Distance, if the intensity values of all pixels are the same within the megaregion, namely $D N=63$ in this case.

(ii) The original core function zones of the Yangtze River Delta and the Pearl River Delta have developed well till 1992 and expand out then. The original core function zones of the Yangtze River Delta and the Pearl River Delta are related to the second (high urbanization, slow development) class of 
$7.24 \%$ and $25.55 \%$ and the fast expansion is related to the first (high urbanization, fast development) class of $45.95 \%$ and $37.91 \%$ (see also Figure 3). On the contrary, the Beijing-Tianjin-Hebei shows decreasing trend in the Gravity Distance which indicates a faster development in the original core function zones although it spatially spreads outwards (see Figure 4 upper row).

(iii) Each individual city is approaching to the overall Geometric Center with decreasing (increasing) Gravity Distance in Beijing-Tianjin-Hebei (Yangtze River Delta and Pearl River Delta). Because the Gravity Center is weighted by light intensity, BTH indicates fast development toward the overall Geometric Center or the original core function zones. That is, the Gravity Distance of the Yangtze River Delta and the Pearl River Delta megaregion indicate light intensity expansion, while the Beijing-Tianjin-Hebei shows light intensity concentration. This appears to be a positive spillover effect of the Yangtze River Delta/Shanghai and the Pearl River Delta/Guangzhou upon their neighbor cities, which is the strongest in the early 21st century and, after adjustment, is followed by a subsequent positive spillover episode.

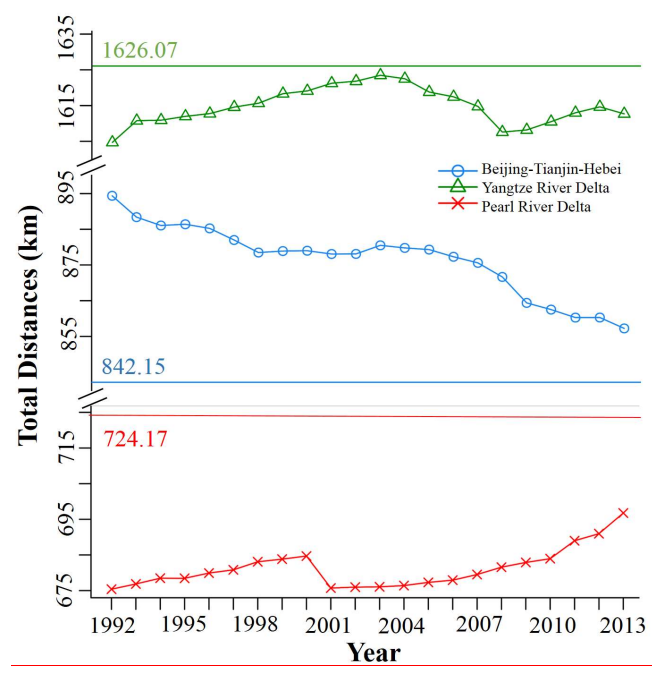

Figure 5. Total distance (Gravity Distance) between the Gravity Center of the megaregion and the Gravity center of internal cities for the three megaregions from 1992 to 2013 . The straight lines and corresponding values mean the total distance (Geometric Distance) between the Geometric Center of megaregion and the Geometric Center of inner cities for the three megaregions in 2013.

\section{Summary and Conclusions}

Urbanization is one of the main driving forces for human social development and natural environmental changes [1,7], which do not only affect the land use on local and regional scales, but also the distribution of resources, population migration, climate change, and ecosystem functioning [3,55-57]. Urbanization induced changes of human settlement and environment ecology, particularly in emerging countries, are associated with complex implications for sustainability and development challenges $[4,6,58]$. There are numerous studies focusing on the spatiotemporal pattern of urbanization in megaregion based on some socioeconomic processes [53,54], but less attention is devoted to the spillover effect from a megaregion on its surrounding cities. To obtain a consistent analysis, the calibrated DMSP/OLS nighttime lights 1992-2013 is applied to the three main megaregions of China. The following results are noteworthy:

(i) The night intensity datasets (light intensity tendency) within the administrative boundary show more like a Gaussian distribution (negative Gaussian) which implies that high (low) values are concentrated in the original urban core function zone, whereas attenuation (amplification) occurs in all surrounding area. That is, highly developed original urban cores show less percentage of the first class (high urbanization, fast development) but high percentage of the second (high urbanization, 
slow development). The 'ring' of amplified light intensity tendency, which occurs in the surroundings of the urban core, shows high percentage of first class (high urbanization, fast development).

(ii) The evolutions of spatial growth patterns (in terms of Weighted Standard Deviational Ellipse based Gravity Center, azimuth, major and minor axes) is used to quantify impacts of anthropogenic activities on land surface dynamics. Within the Beijing-Tianjin-Hebei (Yangtze River Delta versus Pearl River Delta) megaregion, the main construction direction $\theta$ shows a rotation from the $88.59^{\circ}$ to $79.81^{\circ}$ $\left(120.64^{\circ}\right.$ to $133.29^{\circ}$ versus $99.36^{\circ}$ to $91.32^{\circ}$ ). The development ratio (of major over minor axis) of the Beijing-Tianjin-Hebei megaregion decreases before increasing in the major direction to keep a balanced construction. The Yangtze River Delta megaregion reveals a decreasing major and an increasing minor axis length that is associated with a fast development into the minor direction. For the megaregion of Pearl River Delta, the length extensions of both major and minor axes are positively related with some small changes of the development ratio from 1992 to 2013.

(iii) The development level of the original urban cores determines whether a megaregion shows positive/negative spillover effect. The highly developed original urban cores of the Yangtze River Delta and the Pearl River Delta megaregion indicate light intensity expansions, while the less-developed original urban cores of the Beijing-Tianjin-Hebei megaregion shows light intensity concentration. The Gravity Distances describe the spillover effect that the Yangtze River Delta/Shanghai and the Pearl River Delta/Guangzhou reveal the positive spillover effect upon their neighboring cities with a peak in the early 21st century which, after later levelling off, is followed by a subsequent positive spillover episode.

This study characterizes three aspects of the state and evolution of megaregion based on quantitative metrics: (i) light intensity based physical changes of the state and change (or tendency) of human-made structures and materials in the pixel scale, (ii) Standard Deviational Ellipse analysis based spatial expansion and (iii) Gravity Distances based spillover effect on megaregion scale. Note that the related spillover effect is not derived from socioeconomic statistics, but by calculating the light intensity based Gravity Distance from 1992 to 2013. A uniform evaluation concept model based on remote sensing data is applied to analyze megaregion evolution not only spatiotemporally but also socioeconomically $[37,59]$. Thus, it provides a quantitative reference measures for regions that show potential to become megaregions and it supports directing urban planning and conservation resources. Some broader discussion, such as recent concrete developments like the Hong Kong-Macao-Zhuhai Bridge, of the results' implications and relevance would be an informative case study for policy-making.

Author Contributions: X.Z., S.G., Y.G. and D.C. conceived and designed the experiments; X.Z., S.G., Y.G. and D.C. performed the experiments; X.Z., S.G., Y.G. and D.C. analyzed the data; X.Z., Y.G. and D.C. wrote the paper, and all authors contributed to the revising of the manuscript.

Funding: This research was funded by National Natural Science Foundation of China grant number 41501375, and Key Laboratory of Satellite Mapping Technology and Application, National Administration of Surveying, Mapping, and Geoinformation grant number KLSMTA-201710.

Acknowledgments: The authors would also like to extend their acknowledgements to the Max Planck Fellow Group (DC, KF), and anonymous reviewers for improving the manuscript.

Conflicts of Interest: The authors declare no conflict of interest. 


\section{Appendix A}

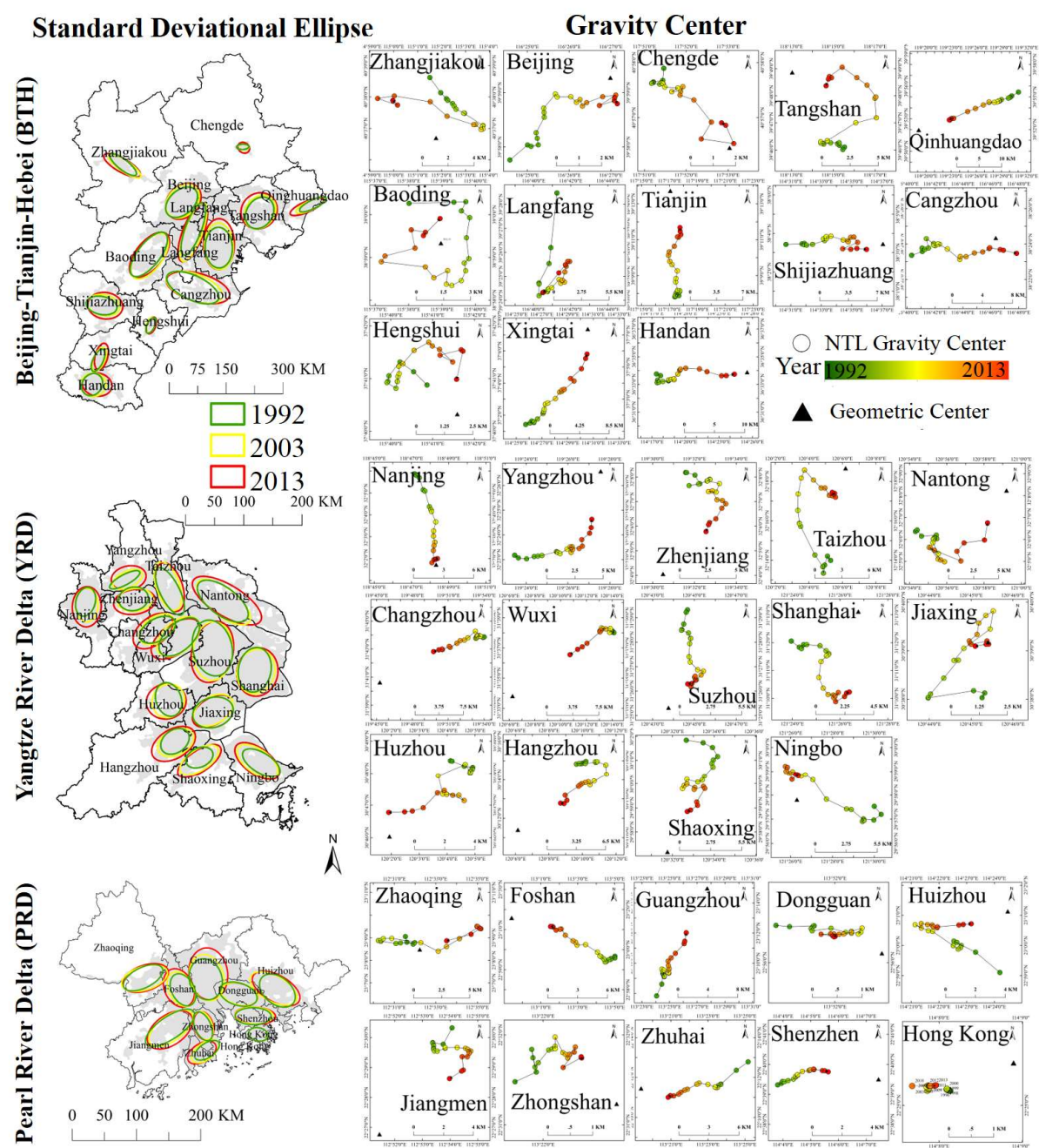

Figure A1. The Weighted Standard Deviational Ellipses (1992, 2003, 2013, left column) and Gravity Center trajectories (from 1992 to 2013, right column) in individual city scale. Note that circles represent the trajectory of the annual Gravity Centers of nighttime lights and the triangles show Geometric Center in 2013.

\section{References}

1. Jordan, M.; Meyer, W.B.; Kates, R.W.; Clark, W.C.; Richards, J.F.; Turner, B.L.; Mathews, J.T. The Earth as Transformed by Human Action: Global and Regional Changes in the Biosphere over the Past 300 Years; CUP Archive: Cambridge, UK, 1990.

2. UN. World Urbanization Prospects: The 2009 Revision; United Nations, Department of Economic and Social Affairs: New York, NY, USA, 2010.

3. Song, X.-P.; Hansen, M.C.; Stehman, S.V.; Potapov, P.V.; Tyukavina, A.; Vermote, E.F.; Townshend, J.R. Global land change from 1982 to 2016. Nature 2018, 560, 639-643. [CrossRef] [PubMed]

4. Cai, D.; Fraedrich, K.; Guan, Y.; Guo, S.; Zhang, C. Urbanization and the thermal environment of Chinese and US-American cities. Sci. Total Environ. 2017, 589, 200-211. [CrossRef] [PubMed]

5. Kuang, W.; Chi, W.; Lu, D.; Dou, Y. A comparative analysis of megacity expansions in China and the U.S.: Patterns, rates and driving forces. Landsc. Urban Plan. 2014, 132, 121-135. [CrossRef]

6. Pickett, S.T.A.; Zhou, W. Global urbanization as a shifting context for applying ecological science toward the sustainable city. Ecosyst. Health Sustain. 2017, 1, 1-15. [CrossRef] 
7. Grimm, N.B.; Faeth, S.H.; Golubiewski, N.E.; Redman, C.L.; Wu, J.; Bai, X.; Briggs, J.M. Global change and the ecology of cities. Science 2008, 319, 756-760. [CrossRef] [PubMed]

8. Seto, K.C.; Reenberg, A.; Boone, C.G.; Fragkias, M.; Haase, D.; Langanke, T.; Marcotullio, P.; Munroe, D.K.; Olah, B.; Simon, D. Urban land teleconnections and sustainability. Proc. Natl. Acad. Sci. USA 2012, 109, 7687-7692. [CrossRef] [PubMed]

9. Harrison, J.; Hoyler, M. Megaregions: Globalization a New Urban Form? Edward Elgar Publishing: Cheltenham, UK, 2015; pp. 1-28.

10. Dewar, M.; Epstein, D. Planning for “Megaregions" in the United States. J. Plan. Lit. 2007, 22, 108-124. [CrossRef]

11. Su, S.; Liu, Z.; Xu, Y.; Li, J.; Pi, J.; Weng, M. China's megaregion policy: Performance evaluation framework, empirical findings and implications for spatial polycentric governance. Land Use Policy 2017, 63, 1-19. [CrossRef]

12. Osman, T.; Divigalpitiya, P.; Arima, T. Driving factors of urban sprawl in Giza Governorate of Greater Cairo Metropolitan Region using AHP method. Land Use Policy 2016, 58, 21-31. [CrossRef]

13. Abrantes, P.; Fontes, I.; Gomes, E.; Rocha, J. Compliance of land cover changes with municipal land use planning: Evidence from the Lisbon metropolitan region (1990-2007). Land Use Policy 2016, 51, 120-134. [CrossRef]

14. Zhou, W.; Zhang, S.; Yu, W.; Wang, J.; Wang, W. Effects of Urban Expansion on Forest Loss and Fragmentation in Six Megaregions, China. Remote Sens. 2017, 9, 991. [CrossRef]

15. Grimm, N.B.; Foster, D.; Groffman, P.; Grove, J.M.; Hopkinson, C.S.; Nadelhoffer, K.J.; Pataki, D.E.; Peters, D.P.C. The changing landscape: Ecosystem responses to urbanization and pollution across climatic and societal gradients. Front. Ecol. Environ. 2008, 6, 264-272. [CrossRef]

16. He, C.; Liu, Z.; Tian, J.; Ma, Q. Urban expansion dynamics and natural habitat loss in China: A multiscale landscape perspective. Glob. Chang. Biol. 2014, 20, 2886-2902. [CrossRef] [PubMed]

17. Gottmann, J. Megalopolis: The Urbanized Northeastern Seaboard of the United States; M.I.T. Press: Cambridge, MA, USA, 1964.

18. Gottmann, J. Megalopolis or the Urbanization of the Northeastern Seaboard. Econ. Geogr. 1957, 33, $189-200$. [CrossRef]

19. Baigent, E. Patrick Geddes, Lewis Mumford and Jean Gottmann: Divisions over 'megalopol is'. Prog. Hum. Geogr. 2004, 28, 687-700. [CrossRef]

20. Ma, T.; Zhou, C.H.; Pei, T.; Haynie, S.; Fan, J.F. Quantitative estimation of urbanization dynamics using time series of DMSP/OLS nighttime light data: A comparative case study from China's cities. Remote Sens. Environ. 2012, 124, 99-107. [CrossRef]

21. Wu, K.-Y.; Zhang, H. Land use dynamics, built-up land expansion patterns, and driving forces analysis of the fast-growing Hangzhou metropolitan area, eastern China (1978-2008). Appl. Geogr. 2012, 34, 137-145. [CrossRef]

22. Dewan, A.M.; Yamaguchi, Y. Land use and land cover change in Greater Dhaka, Bangladesh: Using remote sensing to promote sustainable urbanization. Appl. Geogr. 2009, 29, 390-401. [CrossRef]

23. Huang, X.; Schneider, A.; Friedl, M.A. Mapping sub-pixel urban expansion in China using MODIS and DMSP/OLS nighttime lights. Remote Sens. Environ. 2016, 175, 92-108. [CrossRef]

24. Ju, Y.; Dronova, I.; Ma, Q.; Zhang, X. Analysis of urbanization dynamics in mainland China using pixel-based night-time light trajectories from 1992 to 2013. Int. J. Remote Sens. 2017, 38, 6047-6072. [CrossRef]

25. Ma, T.; Zhou, Y.; Zhou, C.; Haynie, S.; Pei, T.; Xu, T. Night-time light derived estimation of spatio-temporal characteristics of urbanization dynamics using DMSP/OLS satellite data. Remote Sens. Environ. 2015, 158, 453-464. [CrossRef]

26. Yu, W.; Zhou, W. The Spatiotemporal Pattern of Urban Expansion in China: A Comparison Study of Three Urban Megaregions. Remote Sens. 2017, 9, 45. [CrossRef]

27. Zhou, W.; Jiao, M.; Yu, W.; Wang, J. Urban sprawl in a megaregion: A multiple spatial and temporal perspective. Ecol. Indic. 2017. [CrossRef]

28. Elvidge, C.D.; Ziskin, D.; Baugh, K.E.; Tuttle, B.T.; Ghosh, T.; Pack, D.W.; Erwin, E.H.; Zhizhin, M. A Fifteen Year Record of Global Natural Gas Flaring Derived from Satellite Data. Energies 2009, 2, 595-622. [CrossRef]

29. Imhoff, M.L.; Lawrence, W.T.; Stutzer, D.C.; Elvidge, C.D. A technique for using composite DMSP/OLS “city lights" satellite data to map urban area. Remote Sens. Environ. 1997, 61, 361-370. [CrossRef] 
30. Small, C.; Pozzi, F.; Elvidge, C. Spatial analysis of global urban extent from DMSP-OLS night lights. Remote Sens. Environ. 2005, 96, 277-291. [CrossRef]

31. Elvidge, C.D.; Baugh, K.E.; Kihn, E.A.; Kroehl, H.W.; Davis, E.R. Mapping city lights with nighttime data from the DMSP operational linescan system. Photogramm. Eng. Remote Sens. 1997, 63, 727-734.

32. Small, C.; Elvidge, C.D.; Balk, D.; Montgomery, M. Spatial scaling of stable night lights. Remote Sens. Environ. 2011, 115, 269-280. [CrossRef]

33. Frolking, S.; Milliman, T.; Seto, K.C.; Friedl, M.A. A global fingerprint of macro-scale changes in urban structure from 1999 to 2009. Environ. Res. Lett. 2013, 8, 024004. [CrossRef]

34. Ghosh, T.; Anderson, S.J.; Elvidge, C.D.; Sutton, P.C. Using Nighttime Satellite Imagery as a Proxy Measure of Human Well-Being. Sustainability 2013, 5, 4988-5019. [CrossRef]

35. Yu, S.S.; Zhang, Z.X.; Liu, F. Monitoring Population Evolution in China Using Time-Series DMSP/OLS Nightlight Imagery. Remote Sens. 2018, 10, 194. [CrossRef]

36. Amaral, S.; Câmara, G.; Monteiro, A.M.V.; Quintanilha, J.A.; Elvidge, C.D. Estimating population and energy consumption in Brazilian Amazonia using DMSP night-time satellite data. Comput. Environ. Urban Syst. 2005, 29, 179-195. [CrossRef]

37. Doll, C.N.H.; Muller, J.P.; Morley, J.G. Mapping regional economic activity from night-time light satellite imagery. Ecol. Econ. 2006, 57, 75-92. [CrossRef]

38. Su, Y.; Chen, X.; Wang, C.; Zhang, H.; Liao, J.; Ye, Y.; Wang, C. A new method for extracting built-up urban areas using DMSP-OLS nighttime stable lights: A case study in the Pearl River Delta, southern China. GISci. Remote Sens. 2015, 52, 218-238. [CrossRef]

39. Shao, Z.; Liu, C. The Integrated Use of DMSP-OLS Nighttime Light and MODIS Data for Monitoring Large-Scale Impervious Surface Dynamics: A Case Study in the Yangtze River Delta. Remote Sens. 2014, 6, 9359-9378. [CrossRef]

40. Hu, Y.N.; Peng, J.; Liu, Y.; Du, Y.; Li, H.; Wu, J. Mapping Development Pattern in Beijing-Tianjin-Hebei Urban Agglomeration Using DMSP/OLS Nighttime Light Data. Remote Sens. 2017, 9, 760. [CrossRef]

41. Liu, Y.; Wang, Y.; Peng, J.; Du, Y.; Liu, X.; Li, S.; Zhang, D. Correlations between Urbanization and Vegetation Degradation across the World's Metropolises Using DMSP/OLS Nighttime Light Data. Remote Sens. 2015, 7, 2067-2088. [CrossRef]

42. Zhou, B.; Rybski, D.; Kropp, J.P. The role of city size and urban form in the surface urban heat island. Sci. Rep. 2017, 7, 4791. [CrossRef] [PubMed]

43. Zheng, Q.; Jiang, R.; Wang, K.; Huang, L.; Ye, Z.; Gan, M.; Ji, B. Monitoring the trajectory of urban nighttime light hotspots using a Gaussian volume model. Int. J. Appl. Earth Obs. Geoinf. 2018, 65, 24-34. [CrossRef]

44. Guo, G.; Zhou, X.; Wu, Z.; Xiao, R.; Chen, Y. Characterizing the impact of urban morphology heterogeneity on land surface temperature in Guangzhou, China. Environ. Model. Softw. 2016, 84, 427-439. [CrossRef]

45. Wu, J.; He, S.; Peng, J.; Li, W.; Zhong, X. Intercalibration of DMSP-OLS night-time light data by the invariant region method. Int. J. Remote Sens. 2013, 34, 7356-7368. [CrossRef]

46. Liu, Z.; He, C.; Zhang, Q.; Huang, Q.; Yang, Y. Extracting the dynamics of urban expansion in China using DMSP-OLS nighttime light data from 1992 to 2008. Landsc. Urban Plan. 2012, 106, 62-72. [CrossRef]

47. Jenks, G.F. The data model concept in statistical mapping. Int. Yearb. Cartogr. 1967, 7, 186-190.

48. Griffith, D.A. Theory of Spatial Statistics; Springer: Dordrecht, The Netherlands, 1984; pp. 3-15.

49. Lefever, D.W. Measuring Geographic Concentration by Means of the Standard Deviational Ellipse. Am. J. Sociol. 1926, 32, 88-94. [CrossRef]

50. Kang, P.; Chen, W.; Hou, Y.; Li, Y. Linking ecosystem services and ecosystem health to ecological risk assessment: A case study of the Beijing-Tianjin-Hebei urban agglomeration. Sci. Total Environ. 2018, 636, 1442-1454. [CrossRef] [PubMed]

51. Xiao, P.; Wang, X.; Feng, X.; Zhang, X.; Yang, Y. Detecting China's Urban Expansion Over the Past Three Decades Using Nighttime Light Data. IEEE J. Sel. Top. Appl. Earth Obs. Remote Sens. 2014, 7, 4095-4106. [CrossRef]

52. Jia, T.; Chen, K.; Wang, J. Characterizing the Growth Patterns of 45 Major Metropolitans in Mainland China Using DMSP/OLS Data. Remote Sens. 2017, 9, 571. [CrossRef]

53. Krings, G.; Calabrese, F.; Ratti, C.; Blondel, V.D. Urban gravity: A model for inter-city telecommunication flows. J. Stat. Mech. Theory Exp. 2009, 2009, L07003. [CrossRef] 
54. Haynes, K.E.; Fotheringham, A.S. Gravity and spatial interaction models. In Scientific Geography; Regional Research Institute, West Virginia University: Morgantown, MV, USA, 1985.

55. Cai, D.; Fraedrich, K.; Guan, Y.; Guo, S.; Zhang, C.; Zhu, X. Urbanization and climate change: Insights from eco-hydrological diagnostics. Sci. Total Environ. 2018, 647, 29-36. [CrossRef] [PubMed]

56. Jenerette, G.D.; Potere, D. Global analysis and simulation of land-use change associated with urbanization. Landsc. Ecol. 2010, 25, 657-670. [CrossRef]

57. Xiao, H.; Kopecká, M.; Guo, S.; Guan, Y.; Cai, D.; Zhang, C.; Zhang, X.; Yao, W. Responses of Urban Land Surface Temperature on Land Cover: A Comparative Study of Vienna and Madrid. Sustainability 2018, 10, 260. [CrossRef]

58. Zuo, L.; Zhang, Z.; Carlson, K.M.; MacDonald, G.K.; Brauman, K.A.; Liu, Y.; Zhang, W.; Zhang, H.; Wu, W.; Zhao, X. Progress towards sustainable intensification in China challenged by land-use change. Nat. Sustain. 2018, 1, 304-313. [CrossRef]

59. Keola, S.; Andersson, M.; Hall, O. Monitoring Economic Development from Space: Using Nighttime Light and Land Cover Data to Measure Economic Growth. World Dev. 2015, 66, 322-334. [CrossRef]

(C) 2018 by the authors. Licensee MDPI, Basel, Switzerland. This article is an open access article distributed under the terms and conditions of the Creative Commons Attribution (CC BY) license (http:// creativecommons.org/licenses/by/4.0/). 